\title{
Características de carcaça e composição da carne de cordeiros terminados em confinamento com dietas com diferentes níveis de energia
}

\author{
Sérgio Carvalho ${ }^{1}$, Liziany Müller Medeiros ${ }^{1}$ \\ 1 Programa de Pós-graduação em Zootecnia - UFSM, Av. Roraima, 1000, Santa Maria, RS, CEP: 97105-900. \\ RESUMO - Avaliaram-se as características da carcaça, a composição tecidual da secção entre a 9a e a $11^{\mathfrak{a}}$ costela, \\ a composição centesimal do músculo longissimus dorsi e a proporção dos componentes não-carcaça de cordeiros \\ terminados em confinamento com dietas contendo 1,49; 1,55; 1,62; ou 1,68 Mcal de energia líquida/kg de matéria seca. \\ As dietas foram compostas de silagem de milho como volumoso e concentrado composto de um produto comercial e do \\ suplemento energético Lacto Plus ${ }^{\circledR}$. Foram utilizados 16 cordeiros machos não-castrados desmamados aos $74 \pm 18$ dias \\ de idade e abatidos aos 84 dias de confinamento. O delineamento experimental foi o inteiramente casualizado, com quatro \\ níveis de energia, cada um com quatro repetições. A porcentagem de perna diminuiu linearmente, enquanto a porcentagem \\ de costilhar aumentou, também de forma linear, com o aumento do nível de energia na dieta dos cordeiros. A proporção \\ de músculo diminuiu e a de gordura aumentou de acordo com o nível de energia na dieta. A composição centesimal do \\ longissimus dorsi não foi influenciada pelo nível de energia da dieta. As porcentagens de sangue e gordura interna e renal \\ aumentaram linearmente, enquanto as de vísceras cheias e de conteúdo gastrintestinal diminuíram linearmente com o \\ aumento do nível energético das dietas. O aumento do nível de energia líquida na dieta de cordeiros em confinamento \\ reduz a proporção de perna e aumenta a de costilhar, além de aumentar a proporção de gordura e diminuir a de músculo \\ na secção entre a $9 \underline{a}$ e a $11 \underline{a}$ costela.
}

Palavras-chave: carne, composição regional, órgãos internos, ovino

\section{Carcass characteristics and meat composition of lambs finished in feedlot with diets containing different levels of energy}

\begin{abstract}
The objective of this study was to evaluate the characteristics of the carcass, tissue composition in the section between $9^{\text {th }}$ and $11^{\text {th }}$ ribs, centesimal composition of Longissimus dorsi muscle and the proportion of the non-carcass components of non-castrated male lambs, fed in feedlot with diets containing 1.49, 1.55, 1.62 and 1.68 Mcal of net energy/kg of dry matter. Diets were composed by corn silage as the roughage and the concentrate was composed by a commercial ration and the energetic supplement Lacto Plus ${ }^{\circledR}$. It was used sixteen non-castrated male lambs, weaned at $74 \pm 18$ days of age and slaughtered when they completed 84 days of feedlot. A completely ramdomized design was used, with four levels of energy, each one with four replicates. The percentage of leg linearly decreased while the percentage of rib linearly increased as the level of energy in the diet of the lambs improved. There was a linear decrease in the proportion of muscle and linear increase in the proportion of fat according to the level of energy in the diet. The centesimal composition of Longissimus dorsi muscle was not influenced by the level of energy of the diet. The percentages of blood and internal and kidney fat increased linearly while the percentages of full viscera and gastrointestinal content decreased linearly with the increase in energy level in the diets. Increasing levels of net energy in the diet of lambs in feedlot promotes reduction in the proportion of leg and increase the proportion of rib. Additionaly, it promotes an increase in proportion of fat and it reduces the proportion of muscle in the section between the $9^{\text {th }}$ and $11^{\text {th }}$ ribs.
\end{abstract}

Key Words: internal organs, meat, regional composition, sheep

\section{Introdução}

A ovinocultura de corte é uma atividade com significativo crescimento no Brasil, principalmente na produção de cordeiros para abate. Contudo, para que a carne ovina possa competir com a de outras espécies, como aves, suínos e bovinos, o produtor deve colocar no mercado carne de animais jovens (cordeiros), criados de maneira adequada para obtenção de carcaças de primeira qualidade, pois o consumidor está cada vez mais exigente, e busca produtos mais saborosos e saudáveis (Pires et al., 2000). 
Em sistemas extensivos de produção, torna-se difícil obter animais jovens em condições de abate. Para tanto é preciso modificar o meio ambiente, principalmente a alimentação, uma vez que o confinamento é uma alternativa eficaz que tem despertado o interesse dos ovinocultores. Segundo Rodrigues et al. (2008), a estratégia de confinamento encurta o ciclo de produção e coloca no mercado carcaças de animais mais precoces e carne ovina de qualidade. De acordo com Oliveira et al. (2002), a terminação de cordeiros em confinamento apresenta uma série de benefícios, como menor mortalidade dos animais decorrente da menor incidência de verminoses e do maior controle da parte nutricional. Isso proporciona abate precoce e carcaças com alta qualidade, o que reflete em melhores aceitação e preço final. Porém, conforme Pereira et al. (2008), este tipo de criação requer maior investimento em instalações, alimentação e mão-de-obra.

De acordo com Franzolin \& Silva (2001), vários fatores afetam as características de carcaça e a composição corporal dos animais: genética, idade, sexo, nutrição e alimentação, etc. Entre eles, o nível energético da dieta consumida tem grande importância. Conforme descrito por Susin (1996), quando fornecida em excesso, a energia pode aumentar a deposição de gordura na carcaça dos animais, aspecto que contraria a demanda do mercado consumidor.

Outro importante fator a ser considerado na produção de carne ovina é que, conforme Mendonça et al. (2003), a carcaça é o componente do peso vivo de maior valor comercial, entretanto, os demais (pele, cabeça, patas, vísceras verdes e vermelhas), também chamados componentes não-carcaça, frequentemente representam uma parte ponderal mais importante que a carne. Nesse sentido, segundo Osório et al. (1995), há necessidade de valorizar o animal como um todo e, para isso, estudar os componentes do peso vivo.
Assim, objetivou-se estudar o efeito de diversos níveis de energia na dieta sobre as características da carcaça, a composição tecidual da secção entre a 9ạ e a 11aㅡ costela, a composição centesimal do músculo longisimus dorsi e a proporção dos componentes não-carcaça de cordeiros terminados em confinamento.

\section{Material e Métodos}

O experimento foi realizado na Fazenda Sossego Verde, na localidade de São Jacó, no Bairro Lomba Grande, em Novo Hamburgo, RS, no período de 29 de setembro a 21 de dezembro de 2006 utilizando-se 16 cordeiros machos não-castrados, $1 / 2$ Texel + $1 / 2$ SRD (sem raça definida), com $74 \pm 18$ dias de idade e peso vivo inicial de 23,12 \pm 6,04 kg. Os animais foram distribuídos aleatoriamente em quatro dietas, cada uma com um nível de energia, com quatro repetições. Antes da fase experimental, foram identificados com brincos e receberam anti-helmíntico e vacina contra carbúnculo sintomático, gangrena gasosa e enterotoxemia. Os cordeiros foram confinados em baias individuais, totalmente cobertas, com piso ripado e dimensão de $1,5 \mathrm{~m}^{2}$. Todas as baias eram providas de comedouros e bebedouros individuais, onde eram fornecidos alimentos e água para os animais.

As dietas experimentais foram constituídas de silagem de milho, ração comercial (Sano Vitosan - ovino tratador) e Lacto Plus ${ }^{\circledR}$ (suplemento energético que consiste em um sal de cálcio de ácido graxo produzido a partir de gordura vegetal à base de soja), em diferentes proporções (Tabela 1), resultando em diferentes níveis de energia (1,49; 1,55; 1,62; e 1,68 Mcal de energia líquida (EL)/kg de matéria seca) (Tabela 2).

O período experimental foi precedido de um período pré-experimental de 14 dias para adaptação dos animais às instalações, à alimentação e ao manejo. $\mathrm{O}$ alimento foi

Tabela 1 - Composição nutricional dos ingredientes usados nas dietas experimentais

\begin{tabular}{|c|c|c|c|c|c|}
\hline \multirow[t]{2}{*}{ Item } & \multicolumn{5}{|c|}{ Ingrediente } \\
\hline & Silagem de milho & Ração & Sano Vitosan & Lacto Plus ${ }^{\circledR}$ & Calcário calcítico \\
\hline Matéria seca (\%) & 28 & & 87 & 95 & 100 \\
\hline Proteína bruta (\%) & 7 & & 21 & ---- & ---- \\
\hline Fibra em detegente neutro (\%) & 55 & & 9 & ---- & ---- \\
\hline Nutrientes digestíveis totais (\%) & $63^{1}$ & & $70^{2}$ & $175^{2}$ & $-\cdots-$ \\
\hline Energia líquida (Mcal/kg) ${ }^{3}$ & 1,42 & & 1,60 & 4,17 & ---- \\
\hline Fósforo (\%) & 0,21 & & 0,4 & ---- & 0,02 \\
\hline
\end{tabular}

${ }^{1}$ Valor obtido por Ribeiro (1997).

2 Valores fornecidos pela empresa Dalquin Indústria e Comércio Ltda.

${ }^{3}$ Valor calculado segundo Moe \& Tyrrel (1976): $\rightarrow$ EL $=(0,0245 \times \%$ NDT $)-0,12$. 
Tabela 2 - Composição das dietas experimentais

\begin{tabular}{lcccc}
\hline & \multicolumn{4}{c}{$\begin{array}{c}\text { Nível de energia líquida } \\
\text { na dieta (Mcal/kg MS) }\end{array}$} \\
\cline { 2 - 5 } & 1,49 & 1,55 & 1,62 & 1,68 \\
\hline Ingrediente (\%MS) & 47,25 & 45,16 & 43,05 & 41,00 \\
Silagem de milho & 50,90 & 51,60 & 52,32 & 53,00 \\
Ração Sano Vitosan & 0 & 2 & 4 & 6 \\
Lacto Plus ${ }^{\circledR}$ & 1,85 & 1,24 & 0,63 & 0 \\
Calcário calcítico & & & & \\
& & & & \\
Composição nutricional & 59,36 & 60,68 & 62,00 & 63,29 \\
Matéria seca & 14,00 & 14,00 & 14,00 & 14,00 \\
Proteína bruta & 30,57 & 29,48 & 28,39 & 27,32 \\
Fibra em detegente neutro & 65,40 & 68,07 & 70,75 & 73,43 \\
Nutrientes digestíveis totais & 1,79 & 1,79 & 1,79 & 1,79 \\
Cálcio & 0,30 & 0,30 & 0,30 & 0,30 \\
Fósforo & &
\end{tabular}

oferecido à vontade, duas vezes ao dia, às 7h30 e $17 \mathrm{~h} 30$. A quantidade oferecida foi ajustada de acordo com a sobra observada diariamente, que deveria ser de $15 \%$ da quantidade oferecida no dia anterior, de modo a garantir o consumo voluntário máximo dos animais. Nesse sentido, foram realizadas pesagens diárias das sobras e do alimento que seria oferecido pela manhã e pela tarde, para cada animal.

Os cordeiros foram pesados no início e ao final da fase experimental, após jejum de 12 horas, mediante retirada do alimento às $20 \mathrm{~h}$ do dia anterior à pesagem. Para melhor acompanhamento do desempenho, foram realizadas pesagens intermediárias a cada 14 dias. O ensaio de alimentação teve duração de 84 dias, quando então os cordeiros foram abatidos.

O abate ocorreu após a pesagem dos animais em jejum de sólidos e líquidos durante 12 horas. Em cada momento de abate foi coletado todo o sangue e retirados os componentes não-carcaça: pele, patas, cabeça, coração, rins, fígado, pulmão, baço, gordura interna e gordura renal, os quais foram pesados separadamente. Foram também pesadas as vísceras cheias, que, após esvaziamento e minuciosa lavagem, foram pesadas novamente. Por diferença, obteve-se o peso do conteúdo do trato gastrintestinal. Em seguida, calculou-se individualmente a porcentagem dos órgãos internos em relação ao peso vivo dos animais.

Cada carcaça foi pesada individualmente logo após o abate para obtenção do peso da carcaça quente. Em seguida, a carcaça de cada animal foi separada ao meio, com o auxílio de uma serra elétrica, de forma simétrica, longitudinalmente, deixando a cauda no lado esquerdo. Depois de pesadas, as metades direita e esquerda da carcaça foram separadas regionalmente nos seguintes cortes comerciais:

- pescoço: porção entre a secção atlanto-occipital e um corte oblíquo que passa entre a sétima vértebra cervical e a primeira dorsal, em direção à ponta do esterno e terminando na borda inferior do pescoço;

- paleta: membro anterior da carcaça, incluindo a musculatura da escápula e na parte distal a secção ao nível da porção média dos ossos do carpo;

- costilhar: parte da carcaça seccionada entre a última vértebra cervical e a primeira torácica e a última lombar e primeira sacra;

- perna: membro posterior da carcaça, seccionado na articulação da última vértebra lombar e primeira sacra e na porção média do tarso.

Após a separação regional, os diferentes cortes comerciais foram pesados e sua porcentagem calculada em relação ao peso da carcaça. A separação regional foi realizada segundo Osório et al. (1998).

Tabela 3 - Peso vivo ao abate e características de carcaça de cordeiros terminados em confinamento com dietas formuladas com diversos níveis de energia líquida

\begin{tabular}{|c|c|c|c|c|c|c|}
\hline \multirow[t]{2}{*}{ Item } & \multicolumn{4}{|c|}{$\begin{array}{l}\text { Nível de energia líquida na dieta } \\
\text { (Mcal/kg MS) }\end{array}$} & \multirow{2}{*}{$\begin{array}{c}\text { CV } \\
(\%) \\
\end{array}$} & \multirow[t]{2}{*}{ Regressão } \\
\hline & 1,49 & 1,55 & 1,62 & 1,68 & & \\
\hline Peso vivo ao abate (kg) & 42,45 & 41,37 & 40,90 & 45,52 & 18,41 & $\hat{\mathrm{Y}}=42,56$ \\
\hline Peso de carcaça quente (kg) & 19,99 & 18,91 & 20,05 & 21,71 & 21,49 & $\hat{\mathrm{Y}}=20,17$ \\
\hline Rendimento de carcaça quente (\%) & 46,60 & 45,55 & 48,77 & 47,57 & 5,88 & $\hat{\mathrm{Y}}=47,12$ \\
\hline Perna (kg) & 6,546 & 5,966 & 6,205 & 6,784 & 20,86 & $\hat{\mathrm{Y}}=6,375$ \\
\hline Paleta (kg) & 4,059 & 3,612 & 3,990 & 4,256 & 21,79 & $\hat{\mathrm{Y}}=3,979$ \\
\hline Costilhar (kg) & 7,960 & 7,775 & 8,354 & 8,945 & 23,13 & $\hat{\mathrm{Y}}=8,258$ \\
\hline Pescoço (kg) & 1,426 & 1,553 & 1,500 & 1,724 & 19,56 & $\hat{\mathrm{Y}}=1,551$ \\
\hline Perna $(\%)$ & 32,77 & 31,62 & 31,01 & 31,36 & 2,25 & $\hat{\mathrm{Y}}=32,41810-0,24257 E L^{* *} ; R^{2}=0,35$ \\
\hline Paleta (\%) & 20,42 & 19,13 & 19,89 & 19,55 & 4,82 & $\hat{Y}=19,75$ \\
\hline Costilhar (\%) & 39,54 & 41,05 & 41,60 & 41,08 & 2,65 & $\hat{Y}=40,04395+0,25785 E L * ; R^{2}=0,22$ \\
\hline Pescoço (\%) & 7,27 & 8,16 & 7,50 & 8,01 & 9,28 & $\hat{\mathrm{Y}}=7,74$ \\
\hline
\end{tabular}

* $(\mathrm{P}<0,10)$ e ** $(\mathrm{P}<0,05)$ pelo teste $\mathrm{F}$.

$\mathrm{EL}=$ nível de energia líquida na dieta. 
Para determinação da composição tecidual, foi retirada

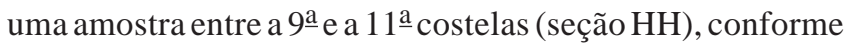
procedimento descrito em Hankins \& Howe (1946). Então, estas amostras foram identificadas, acondicionadas em saco plástico e congeladas para posterior análise. Depois de descongeladas, as amostras foram pesadas e dissecadas em osso, músculo e gordura. Cada um dos componentes teciduais foi pesado para cálculo do peso relativo, em relação à amostra total. Feito isto, o músculo longissimus dorsi foi separado para determinação da composição centesimal. Assim, foram determinados a umidade e os teores de proteína bruta, e de gordura e cinzas, conforme procedimentos descritos por Carvalho \& Jong (2002).

O delineamento experimental utilizado foi o inteiramente casualizado, com quatro tratamentos e quatro repetições, considerando cada cordeiro uma unidade experimental. Os dados foram submetidos a análise de regressão, com auxílio do pacote estatístico SAS (1997). Os modelos foram selecionados com base nos coeficientes de determinação e na significância dos coeficientes de regressão, adotando-se o nível de 10\% de probabilidade, pelo teste F.

\section{Resultados e Discussão}

A porcentagem de perna diminuiu linearmente $(\mathrm{P}<0,05)$, enquanto a de costilhar aumentou, também linearmente $(\mathrm{P}<0,1)$, de acordo com o nível de energia nas dietas (Tabela 3). Esse resultado confirma a afirmativa de Kempster et al. (1987) de que a deposição de gordura na carcaça é mais rápida no lombo e costilhar, que nos outros cortes comerciais, o que no caso do costilhar, está associado à maior deposição de gordura nesta região nos animais alimentados com dietas mais energéticas. Neste sentido, Osório (1992) citou uma relação entre a composição regional e a composição tecidual da carcaça de cordeiros,uma vez que o aumento da proporção de gordura na carcaça eleva a proporção de costilhar com maior proporção de músculo na carcaça, aumenta a proporção de perna. A diminuição na proporção de perna é um aspecto produtivo importante, pois, de acordo com Pilar et al. (2006), os cortes da carcaça têm diferentes valores econômicos, enquanto perna ou pernil é o mais valorizado, sua proporção constitui importante índice para avaliação da qualidade comercial da carcaça.

Os valores médios de peso vivo ao abate e peso de carcaça quente, 42,56 e 20,17 kg, respectivamente, foram satisfatórios para cordeiros abatidos aos $158 \pm 18$ dias. Os resultados são superiores aos obtidos por Carvalho et al. (2007), que testando sistemas alimentares na terminação de cordeiros da raça Texel abatidos aos 144 dias de idade, observaram no sistema de confinamento valor médio de $33,90 \mathrm{~kg}$ para peso vivo ao abate e de 15,10 kg para peso de carcaça quente. Foram superiores também aos valores obtidos por Pires et al. (1999), que verificaram valor médio de 31,09 kg para peso vivo ao abate e de 12,15 kg para peso de carcaça quente em cordeiros $1 / 2$ Texel aos 3 e 4 meses de idade e abatidos após 85 dias de confinamento.

A avaliação da proporção dos cortes comerciais realizados na carcaça dos animais, comprova que os valores médios obtidos (Tabela 3) estão de acordo com os relatados por Tonetto et al. (2004), que observaram em cordeiros $1 / 2$ Texel terminados em confinamento valores médios de $33,41 \%$ para perna, $19,53 \%$ para paleta, 37,61\% para costilhar e 9,29\% para pescoço. Valores semelhantes também foram observados por Pires et al. (2006), que testaram diferentes níveis de fibra em detergente neutro na dieta de cordeiros terminados em confinamento e verificaram valores médios de 33,99\% para perna, 20,25\% para paleta, 37,05\% para costilhar e 9,39\% para pescoço, e por Brochier \& Carvalho (2009), que obtiveram, em cordeiros da raça Texel terminados em confinamento com dietas contendo resíduo úmido de cervejaria, valores médios de 33,64\% para perna, 20,03\% para paleta, 36,26\% para costilhar e $8,82 \%$ para pescoço.

Neste estudo, optou-se por determinar a composição tecidual da secção entre a $9^{\underline{a}}$ e a $11^{a}$ costelas (seção HH) adotando-se a metodologia descrita por Hankins \& Howe (1946), utilizada para determinação indireta da composição tecidual em bovinos. Vários autores utilizaram partes da carcaça de ovinos como representativo de sua composição tecidual, pois, segundo Souza (1993), a dissecação de toda a carcaça, ou de metade apenas, só se justifica em casos especiais, por ser onerosa, trabalhosa e lenta. Portanto, neste estudo, adotou-se a seção HH para determinação da composição tecidual enfatizando-se que os resultados obtidos neste estudo são apenas para essa secção e serve como comparativo da composição da carcaça dos cordeiros como um todo.

Houve diminuição linear na proporção de músculo e crescimento linear na proporção de gordura à medida que aumentou o nível de energia na dieta (Tabela 4). Esse resultado obtido está de acordo com a afirmativa de Kempester et al. (1986) de que, entre os componentes teciduais da carcaça, o músculo e a gordura variam de forma inversa. Deve-se destacar que o aumento na proporção de gordura no maior nível de energia da dieta pode ser um aspecto negativo relacionado ao sistema produtivo, pois segundo Pelegrini (2007), o consumidor vem direcionando sua alimentação conforme sua saúde, e um dos fatores 
preocupantes e de motivo de rejeição ao consumo é a presença excessiva de gordura.

A mesma tendência observada neste estudo foi verificada por Brochier \& Carvalho (2009), que testaram dietas contendo resíduo úmido de cervejaria na terminação de cordeiros da raça Texel em sistema de confinamento as dietas continham níveis de energia líquida variando entre 1,29 e 1,55 Mcal/kg e verificou que o aumento do teor de resíduo e a diminuição da energia líquida da dieta promoveram aumento linear na proporção de músculo $(\mathrm{P}<0,05)$ e redução numérica na proporção de gordura da secção entre a 9aㅡ e a $11^{\underline{a}}$ costela.

Pires et al. (1999) verificaram em cordeiros Texel × Ideal, machos não-castrados, terminados em confinamento e abatidos aos 100 dias de idade valores médios de 22,04\% para osso, 62,70\% para músculo e 16,40\% para gordura na carcaça dos animais. Em outro estudo, Rosa et al. (2002) compararam a composição tecidual da carcaça e de seus cortes em cordeiros da raça Texel e observaram valores de 19,43\% para osso, 61,90\% para músculo e de 18,07\% para gordura na carcaça de cordeiros machos não-castrados terminados em confinamento. Já Siqueira et al. (2001), avaliando o efeito do sexo e do peso de abate sobre a produção de carne de cordeiros, observaram no lombo de cordeiros machos não-castrados, desmamados aos 60 dias de idade valores médios de 16,98\% para osso, 56,13\% para músculo e $21,79 \%$ para gordura.

De maneira geral, os valores obtidos neste trabalho são superiores aos observados na literatura para proporção de gordura e inferiores aos observados para proporção de músculo, porém próximos quanto à proporção de osso. Isso indica que os cordeiros apresentavam excesso de gordura na carcaça, um aspecto negativo do ponto de vista produtivo, pois pode levar à rejeição do produto final pelo consumidor.

Não foi observado efeito do nível de energia da dieta sobre nenhuma das variáveis analisadas em relação à composição centesimal do músculo longissimus dorsi (Tabela 5). Os valores médios verificados neste estudo estão de acordo com relatos de Prata (1999), que observou na composição centesimal da carne de cordeiros $75 \%$ de umidade, 19\% de proteína bruta, 4\% de gordura e 1,1\% de cinzas.

Monteiro et al. (2001) avaliaram a composição centesimal do músculo longissimus dorsi de cordeiros mestiços Texel $\times$ Corriedale criados em regime de pasto e abatidos aos 270 dias de idade e encontraram valores próximos aos deste experimento para umidade $(73,8 \%)$ e cinzas $(1,0 \%)$, entretanto, para os teores de proteína (22,0\%) e gordura $(3,2 \%)$, os valores observados por esses autores foram superior e inferior, respectivamente, aos deste estudo. Em outro estudo, Klein Jr. et al. (2006) avaliaram a composição centesimal do músculo longissimus lumborum de cordeiros mestiços com predominância da raça Ideal, nãocastrados, desmamados aos 70 dias de idade e mantidos em confinamento até o abate com peso vivo médio de $37 \mathrm{~kg}$, e verificaram valores médios similares (71,96\% de umidade; 20,61\% de proteína, 5,51\% de gordura e 1,12\% de cinzas).

As proporções de sangue, gordura interna e gordura renal aumentaram linearmente, enquanto as de vísceras cheias e de conteúdo gastrintestinal diminuíram linearmente com o aumento dos níveis de energia nas dietas (Tabela 6).

O comportamento encontrado para gordura interna e renal está de acordo com relatos de Alves et al. (2003), que avaliaram o efeito dos níveis de energia na dieta sobre as características da carcaça e os constituintes corporais de cordeiros da raça Santa Inês, e observaram mesma tendência deste estudo. Esses autores também citam que a gordura é o componente com maior variação decorrente do nível nutricional, e que a maior proporção de gordura interna acarreta, na prática, maiores exigências de energia para mantença, em razão da maior atividade metabólica do tecido adiposo. Neste sentido, considerando que a gordura interna não é aproveitada para consumo humano, há

Tabela 4 - Pesos e proporções de osso, músculo e gordura da secção entre a $9 \underline{a}$ e a $11^{a}$ a costela de cordeiros terminados em confinamento com dietas contendo diversos níveis de energia

\begin{tabular}{|c|c|c|c|c|c|c|}
\hline \multirow[t]{2}{*}{ Item } & \multicolumn{4}{|c|}{$\begin{array}{l}\text { Nível de energia líquida na dieta } \\
\text { (Mcal/kg MS) }\end{array}$} & \multirow{2}{*}{$\begin{array}{l}\text { CV } \\
(\%)\end{array}$} & \multirow[t]{2}{*}{ Regressão } \\
\hline & 1,49 & 1,55 & 1,62 & 1,68 & & \\
\hline Osso (g) & 37,90 & 37,00 & 38,94 & 69,65 & 44,42 & $\hat{\mathrm{Y}}=46,47$ \\
\hline Músculo (g) & 116,67 & 116,33 & 116,41 & 125,41 & 17,76 & $\hat{\mathrm{Y}}=118,87$ \\
\hline Gordura (g) & 52,59 & 80,87 & 67,36 & 96,62 & 39,79 & $\hat{\mathrm{Y}}=73,93$ \\
\hline Osso (\%) & 19,12 & 14,90 & 17,26 & 23,39 & 28,78 & $\hat{\mathrm{Y}}=18,92$ \\
\hline Músculo (\%) & 55,82 & 51,16 & 52,58 & 44,24 & 12,18 & $\hat{\mathrm{Y}}=56,11084-1,68745 \mathrm{EL} * * ; \mathrm{R}^{2}=0,31$ \\
\hline Gordura (\%) & 25,05 & 33,94 & 30,16 & 32,38 & 15,54 & $\hat{\mathrm{Y}}=27,17030+0,97012 \mathrm{EL} * ; \mathrm{R}^{2}=0,21$ \\
\hline
\end{tabular}

* $(\mathrm{P}<0,10)$ e ** $(\mathrm{P}<0,05)$ pelo teste $\mathrm{F}$.

$\mathrm{EL}=$ nível de energia líquida na dieta. 
Tabela 5 - Composição centesimal (g/100g) do músculo longissimus dorsi de cordeiros terminados em confinamento com dietas formuladas com diversos níveis de energia

\begin{tabular}{lcccccc}
\hline Item & Nível de energia líquida na dieta & \\
& \multicolumn{9}{c}{ (Mcal/kg MS) } & CV & Regressão \\
\cline { 2 - 5 } & 1,49 & 1,55 & 1,62 & 1,68 & $(\%)$ & \\
\hline Umidade & 74,68 & 75,23 & 74,06 & 74,16 & 2,09 & $\hat{Y}=74,49$ \\
Proteína bruta & 19,53 & 18,47 & 19,20 & 20,15 & 6,67 & $\hat{Y}=19,40$ \\
Gordura & 4,91 & 5,48 & 5,83 & 4,74 & 18,93 & $\hat{Y}=5,22$ \\
Cinzas & 0,88 & 0,82 & 0,90 & 0,95 & 16,48 & $\hat{Y}=0,89$ \\
\hline
\end{tabular}

desperdício de energia alimentar que poderia estar direcionada para produção de outros componentes corporais comestíveis. Além disso, com o aumento da gordura interna, provavelmente aumentará a gordura depositada na carcaça dos animais, como verificado neste estudo, ou seja, crescimento na proporção de gordura da secção entre a 9a e a 11 $\underline{\text { a }}$ costelas à medida que se elevou o nível de energia nas dietas (Tabela 4).

$\mathrm{O}$ resultado referente à diminuição da proporção de vísceras cheias está relacionado à redução da proporção de conteúdo gastrintestinal à medida que se elevou o nível de energia das dietas, uma vez que não foi verificado efeito sobre a proporção de vísceras vazias. Segundo Mertens (1992), entre os fatores que influenciam a proporção de conteúdo gastrintestinal, encontra-se o teor de fibra em detergente neutro (FDN) das dietas, uma vez que as rações com menores teores de energia apresentam maiores teores de fibra e maior digestibilidade, aumentando o tempo de retenção do alimento no rúmen e de conteúdo gastrintestinal no momento do abate. Contudo, neste estudo, havia uma pequena variação no teor de fibra em detergente neutro entre as dietas (Tabela 2), o que leva a inferir que, conforme relatado por Mertens (1983), a redução na proporção de vísceras cheias e de conteúdo gastrintestinal ocorreu devido a uma regulação fisiológica do consumo que ocorre à medida que se eleva a energia da dieta em ruminantes.

Os resultados deste estudo estão de acordo com os relatos de Carvalho et al. (2007), os quais observaram em cordeiros da raça Texel terminados em confinamento e abatidos aos 144 dias de idade valores médios de 3,64\% para sangue, $10,10 \%$ para pele, $1,91 \%$ para patas, $3,70 \%$ para cabeça, $0,41 \%$ para coração, $0,28 \%$ para rins, $1,75 \%$ para fígado, 2,19\% para pulmão + traqueia e $0,13 \%$ para baço. Contudo, valores inferiores foram observados por estes autores para gordura interna e renal de $0,42 \%$ e $0,50 \%$, respectivamente. Em outro estudo Furusho-Garcia et al. (2003), encontraram resultados próximos aos deste estudo. Esses autores avaliaram os componentes corporais e órgãos internos de cordeiros de diferentes genótipos terminados em confinamento com casca de café como parte da dieta, e observaram em cordeiros Texel $\times$ Santa Inês valores médios de $4,02 \%$ para sangue, 9,83\% para pele, $2,18 \%$ para patas, $3,54 \%$ para cabeça, $0,38 \%$ para coração, $1,69 \%$ para fígado e $0,15 \%$ para baço.

Tabela 6 - Componentes não-carcaça de cordeiros terminados em confinamento com dietas contendo diversos níveis de energia

\begin{tabular}{|c|c|c|c|c|c|c|}
\hline \multirow{2}{*}{$\begin{array}{l}\text { Componente } \\
\text { (\% do peso vivo) }\end{array}$} & \multicolumn{4}{|c|}{$\begin{array}{l}\text { Nível de energia líquida na dieta } \\
\text { (Mcal/kg MS) }\end{array}$} & \multirow{2}{*}{$\begin{array}{l}\mathrm{CV} \\
(\%)\end{array}$} & \multirow[t]{2}{*}{ Regressão } \\
\hline & 1,49 & 1,55 & 1,62 & 1,68 & & \\
\hline Sangue & 3,34 & 3,71 & 3,69 & 4,28 & 14,31 & $\hat{\mathrm{Y}}=3,33525+0,14012 \mathrm{EL}^{* *} ; \mathrm{R}^{2}=0,28$ \\
\hline Pele & 10,86 & 11,62 & 10,28 & 11,78 & 13,36 & $\hat{\mathrm{Y}}=11,14$ \\
\hline Patas & 1,85 & 1,77 & 1,80 & 1,88 & 7,35 & $\hat{\mathrm{Y}}=1,82$ \\
\hline Cabeça & 3,28 & 3,24 & 3,27 & 3,27 & 8,71 & $\hat{\mathrm{Y}}=3,26$ \\
\hline Coração & 0,38 & 0,37 & 0,37 & 0,37 & 6,11 & $\hat{Y}=0,37$ \\
\hline Rins & 0,24 & 0,23 & 0,22 & 0,23 & 11,02 & $\hat{Y}=0,23$ \\
\hline Fígado & 1,56 & 1,68 & 1,71 & 1,70 & 8,29 & $\hat{\mathrm{Y}}=1,66$ \\
\hline Pulmão+traqueia & 1,91 & 1,96 & 1,80 & 2,03 & 9,88 & $\hat{Y}=1,92$ \\
\hline Baço & 0,13 & 0,14 & 0,14 & 0,13 & 15,57 & $\hat{Y}=0,14$ \\
\hline Gordura intestinal & 1,24 & 1,69 & 1,49 & 1,87 & 26,06 & $\hat{\mathrm{Y}}=1,32050+0,08400 \mathrm{EL} * ; \mathrm{R}^{2}=0,39$ \\
\hline Gordura renal & 0,90 & 1,25 & 1,150 & 1,23 & 17,51 & $\hat{\mathrm{Y}}=1,00100+0,04425 \mathrm{EL} * \mathrm{R}^{2}=0,22$ \\
\hline Visceras cheias & 25,77 & 23,63 & 21,41 & 22,11 & 13,68 & $\hat{Y}=25,20950-0,65962 E L^{*} ; R^{2}=0,20$ \\
\hline Visceras vazias & 6,60 & 6,94 & 6,53 & 6,88 & 8,97 & $\hat{Y}=6,74$ \\
\hline Conteúdo gastrintestinal & 19,17 & 16,68 & 14,88 & 15,23 & 17,10 & $\hat{\mathrm{Y}}=18,53750-0,68125 E L^{* *} ; \mathrm{R}^{2}=0,25$ \\
\hline
\end{tabular}

* $(\mathrm{P}<0,10)$ e ** $(\mathrm{P}<0,05)$ pelo teste $\mathrm{F}$.

$\mathrm{EL}=$ nível de energia líquida na dieta. 


\section{Conclusões}

O aumento dos níveis de energia líquida na dieta de cordeiros em sistema de confinamento ocasiona alterações na composição dos cortes. Entre elas, redução nas proporções de perna e músculo na secção entre a $9^{a}$ e a $11^{\mathrm{a}}$ costelas e aumento nas proporções de costilhar e de gordura, aspectos que vão contra a demanda do mercado consumidor.

\section{Agradecimentos}

À empresa Dalquim Indústria e Comercio Ltda, pelo fornecimento do alimento concentrado e do suplemento energético utilizados; ao Sr. Valdir Daltrozo, pelos animais e pela infra-estrutura necessária para condução deste estudo; aos alunos Taís Dufau de Vargas e Fábio Dioclei Daltrozo, pelo auxílio na condução do experimento; e ao Centro Universitário Feevale, pelo apoio oferecido.

\section{Referências}

ALVES, K.S.; CARVALHO, F.F.R.; FERREIRA, M.A. et al. Níveis de energia em dietas para ovinos Santa Inês: características de carcaça e constituintes corporais. Revista Brasileira de Zootecnia, v.32, n.6, p.1927-1936, 2003 (supl. 2).

BROCHIER, M.A.; CARVALHO, S. Efeito de diferentes proporções de resíduo úmido de cervejaria sobre as características da carcaça de cordeiros terminados em confinamento. Arquivo Brasileiro de Medicina Veterinária e Zootecnia, v.61, n.1, p.190-195, 2009.

CARVALHO, H.H.; JONG, E.V. Alimentos - métodos físicos e químicos de análise. Porto Alegre: UFRGS, 2002. 180p.

CARVALHO, S.; BROCHIER, M.A. Composição tecidual e centesimal e teor de colesterol da carne de cordeiros terminados em confinamento com dietas contendo níveis crescentes de resíduo úmido de cervejaria. Ciência Rural, v.38, n.7, p.2023-2028, 2008.

CARVALHO, S.; BROCHIER, M.A.; PIVATO, J. et al. Ganho de peso, características da carcaça e componentes não-carcaça de cordeiros da raça Texel terminados em diferentes sistemas alimentares. Ciência Rural, v.37, n.3, p.821-827, 2007.

FRANZOLIN, R.; SILVA, J.R. Níveis de energia na dieta de bubalinos em crescimento alimentados em confinamento: 2. Características de carcaça. Revista Brasileira de Zootecnia, v.30, n.6, p.1880-1885, 2001.

FURUSHO-GARCIA, I.F.; PEREZ, J.R.O.; OLIVEIRA, M.V.M. Componentes corporais e órgãos internos de cordeiros Texel x Bergamácia, Texel x Santa Inês e Santa Inês puros, terminados em confinamento, com casca de café como parte da dieta. Revista Brasileira de Zootecnia, v.32, n.6, p.1992-1998, 2003 (supl. 2).

HANKINS, O.G.; HOWE, P.E. Estimation of the composition of beef carcasses and cuts. Washington: United Sates Department of Agriculture, 1946. p.1-19 (Technical Bulletin USDA, 926).

KEMPSTER, A.J.; COOK, G.L.; GRANTLEY-SMITH, M. National estimates of the body composition of British cattle, sheep and pigs with special references to trends in fatness: a review. Meat Science, v.17, n.2, p.107-138, 1986.
KEMPSTER, A.J.; CROSTON, D.; GUY, D.R. et al. Growth and carcass characteristics of crossbred lambs by tem sire breeds, compared at the same estimated carcass subcutaneous fat proportion. Animal Production, v.44, n.1, p.83-98, 1987.

KLEIN JR., M.H.; SIQUEIRA, E.R.; ROÇA, R.O. Qualidade da carne de cordeiros castrados e não castrados confinados sob dois fotoperíodos. Revista Brasileira de Zootecnia, v.35, n.4, p.1872-1879, 2006 (supl.).

MENDONÇA, G.; OSÓRIO, J.C.; OLIVEIRA, N.M. et al. Morfologia, características da carcaça e componentes do peso vivo em borregos Corriedale e Ideal. Ciência Rural, v.33, n.2, p.351-355, 2003.

MERTENS, D.R. Using neutral detergent fiber to formulate dairy rations and estimate the net energy content of forages. Ithaca: Cornell University, 1983. p.60-69.

MERTENS, D.R. Análise da fibra e sua utilização na avaliação e formulação de rações. In: SIMPÓSIO INTERNACIONAL DE RUMINANTES, 29., 1992, Lavras. Anais... Lavras: Sociedade Brasileira de Zootecnia, 1992. p.188-219.

MOE, P.W.; TYRRELL, H.F. Estimating metabolizable and net energy of feeds. In: INTERNATIONAL SYMPOSIUM ON FEED COMPOSITION, ANIMAL NUTRIENT REQUIREMENTS, AND COMPUTERIZATION OF DIETS, 1., 1967, Logan. Proceedings... Logan: Utah State University, 1976. p.232-237.

MONTEIRO, E.M.; RÜBENSAM, J.; PIRES, G. Avaliação de parâmetros de qualidade da carcaça e da carne de ovinos. In: CONGRESSO BRASILEIRO DE CIÊNCIA E TECNOLOGIA DE CARNES, 1., 2001, São Pedro. Anais... São Pedro: CTC/ITAL, 2001. p.98-99.

OLIVEIRA, M.V.M.; PÉREZ, J.R.O.; ALVES, E.L. et al. Avaliação da composição de cortes comerciais, componentes corporais e órgãos internos de cordeiros confinados e alimentados com dejetos de suínos. Revista Brasileira de Zootecnia, v.31, n.3, p.1459-1468, 2002 (supl.).

OSÓRIO, J.C.S. Estudio de la calidad de canales comercializadas en el tipo ternasco según la procedencia: bases para la mejora de dicha calidad en Brasil. 1992. 335f. Tese (Doutorado em Veterinária) - Universidad de Zaragoza, Zaragoza.

OSÓRIO, J.C.; SIERRA, I.; SAÑUDO, C. et al. Componentes do peso vivo em cordeiros e borregos Polwarth e cruzas Texel $\mathrm{x}$ Polwarth. Ciência Rural, v.25, n.1, p.139-143, 1995.

OSÓRIO, J.C.S.; OSÓRIO, M.T.; JARDIM, P.O. et al. Métodos para avaliação de produção de carne ovina: in vivo, na carcaça e na carne. Pelotas: Editora Universitária/UFPEL, 1998. $107 \mathrm{p}$.

Pelegrini, L.F.V. Perfil de ácidos graxos, embutido fermentado e características da carcaça de ovelhas de descarte. 2007. 71f. Tese (Doutorado em Zootecnia) Universidade Federal de Santa Maria, Santa Maria.

PEREIRA, M.S.; RIBEIRO, E.L.A.; MIZUBUTI, I.Y. et al. Consumo de nutrientes e desempenho de cordeiros em confinamento alimentados com dietas com polpa cítrica úmida prensada em substituição à silagem de milho. Revista Brasileira de Zootecnia, v.37, n.1, p.134-139, 2008.

PILAR, R.C.; PÉREZ, J.R.O.; NUNES, F.M. Composição relativa dos cortes da carcaça de cordeiros Merino Australiano e cruza Ile de France $x$ Merino Australiano abatidos com diferentes pesos. Revista Brasileira de Agrociência, v.12, n.4, p.461-469, 2006.

PIRES, C.C.; ARAÚJO, J.R.; BERNARDES, R.A.C. et al. Desempenho e características da carcaça de cordeiros de três grupos genéticos abatidos ao mesmo estágio de maturidade. Ciência Rural, v.29, n.1, p.155-158, 1999.

PIRES, C.C.; CARVALHO, S.; GRANDI, A. et al. Características quantitativas e composição tecidual da carcaça de cordeiros terminados em confinamento. Ciência Rural, v.29, n.3, p.539-543, 1999. 
PIRES, C.C.; SILVA, L.F.; SCHLICK, F.E. et al. Cria e terminação de cordeiros confinados. Ciência Rural, v.30, n.5, p.875-880, 2000.

PIRES, C.C.; GALVANI, D.B.; CARVALHO, S. et al. Características da carcaça de cordeiros alimentados com dietas contendo diferentes níveis de fibra em detergente neutro. Revista Brasileira de Zootecnia, v.35, n.5, p.2058-2065, 2006.

PRATA, L.F. Higiene e inspeção de carnes, pescado e derivados. Jaboticabal: FUNEP, 1999. 217p.

RIBEIRO, S.D.A. Caprinocultura: criação racional de caprinos. São Paulo: Nobel, 1997. 318p.

RODRIGUES, G.H.; SUSIN, I.; PIRES, A.V. et al. Polpa cítrica em rações para cordeiros em confinamento: características da carcaça e qualidade da carne. Revista Brasileira de Zootecnia, v.37, n.10, p.1869-1875, 2008.

ROSA, G.T.; PIRES, C.C.; SILVA, J.H.S. et al. Composição tecidual da carcaça e de seus cortes e crescimento alométrico do osso, músculo e gordura da carcaça de cordeiros da raça Texel. Acta Scientiarum, v.24, n.4, p.1107-1111, 2002.
SIQUEIRA, E.R.; SIMÕES, C.D.; FERNANDES, S. Efeito do sexo e do peso ao abate sobre a produção de carne de cordeiro: morfometria da carcaça, pesos dos cortes, composição tecidual e componentes não constituintes da carcaça. Revista Brasileira de Zootecnia, v.30, n.4, p.1299-1307, 2001.

SOUZA, O.R.C. Rendimento de carcaça, composição regional e física da paleta e quarto em cordeiros Romney Marsh abatidos aos 90 e 180 dias de idade. 1993. 102f. Dissertação (Mestrado em Zootecnia) - Universidade Federal de Pelotas, Pelotas. STATISTICAL ANALYSIS SYSTEMS - SAS. User's guide: Version 6. Cary: v.2, 1997. 1052p.

SUSIN, I. Exigências nutricionais de ovinos e estratégias de alimentação. In: SILVA SOBRINHO, A.G.; BATISTA, A.M.V.; SIQUEIRA, E.R. et al. (Eds.) Nutrição de ovinos. Jaboticabal: Fundação Estadual Paulista, 1996. 258p.

TONETTO, C.J.; PIRES, C.C.; MÜLLER, L. et al. Rendimentos de cortes da carcaça, Características da carne e componentes do peso vivo em cordeiros terminados em três sistemas de alimentação. Revista Brasileira de Zootecnia, v.33, n.1, p.234-241, 2004 (supl.). 